\title{
Effect of ion concentration on mechanosynthesis of carbonated chlorapatite nanopowders
}

\author{
Abbas Fahami ${ }^{\mathrm{a}, *}$, Bahman Nasiri-Tabrizi ${ }^{\mathrm{b}, * *}$, Gary W. Beall ${ }^{\mathrm{c}, \mathrm{d}}$, Belinda Pingguan-Murphy ${ }^{\mathrm{b}}$ \\ a Ingram School of Engineering and Materials Science, Engineering and Commercialization Program, Texas State University, San Marcos, 78666 TX, USA \\ bepartment of Biomedical Engineering, Faculty of Engineering, University of Malaya, 50603 Kuala Lumpur, Malaysia \\ ${ }^{c}$ Texas State University, Department of Chemistry and Biochemistry, 601 University Drive, San Marcos, 78666 TX, USA \\ d Physics Department, Faculty of Science, King Abdulaziz University, Jeddah 21589, Saudi Arabic
}

A R T I C L E I N F O

\section{Article history:}

Received 10 November 2014

Accepted 24 January 2015

Available online 7 February 201

Keywords:

Bioceramics

X-ray techniques

FTIR

Electron microscopy

Nanoparticles

\begin{abstract}
A B S T R A C T
Carbonated chlorapatite nanopowders (n-CCAp) with different degrees of substitution were successfully synthesized by the one-step mechanochemical process. Results demonstrated that the formation of n-CCAp was influenced strongly by the carbonate content $(x)$. From X-ray analysis, crystallite size, crystallinity degree, and unit cell volume of $\mathrm{n}$-CCAp decreased significantly as carbonate content $(x)$ increased from 0 to 2 . Conversely, the lattice strain and the volume fraction of grain boundaries grew considerably. Microscopic analysis showed the average particle size of the synthesized powders was $15 \pm 10 \mathrm{~nm}$. The influence of carbonate concentration on mechanosynthesis of pure n-CCAp utilizing a facile solid-state process has not been reported yet; it has potential application for biomedical engineering.

c) 2015 Elsevier B.V. All rights reserved.
\end{abstract}

\section{Introduction}

Minor amounts of carbonate are valuable and certainly essential, constituents of the hydroxyapatite of human dental enamel and cortical bone [1]. Perhaps the greatest fascinating trait of the apatites is their extraordinary ability to undergo isomorphous substitution by a large variety of cations and anions. The incorporation of carbonate into the apatite structure can happen by substitution for the monovalen anion (A-type substitution of one $\mathrm{CO}_{3}^{2-}$ for two $\mathrm{X}^{-}$) or by substitution for phosphate (B-type substitution $\mathrm{CO}_{3}^{2-}$ for $\mathrm{PO}_{4}^{3-}$ ), the latter of which requires loss of both monovalent anions and cations to preserve charge neutrality [2]. These kind of apatite structures form a bioactive apatite with higher dissolution and osteoclast mediated resorption properties [3]. Furthermore, the presence of carbonate into the apatite structure leads to a decline in crystallinity, a change in crystal morphology, and an enhancement of chemical reactivity due to the weak bonding due to carbonates geometry [4-6]. In fact, the carbonated apatite boosts the local concentration of calcium and phosphate ions that are necessary for new bone formation [7]. For all these reasons, the production of carbonated hydroxyapatite and carbonated fluorapatite is of great value and has been broadly scrutinized using different synthesis processes such as precipitation, sol-gel, solidstate reaction, and hydrothermal treatment [8].

*Corresponding author. Tel.: + 15129600009; fax: + 15122453675

* Corresponding author. Tel: + 60 379674491: fax: + 60379674579

E-mail addresses: fahami@txstate.edu (A. Fahami). bahman_nasiri@hotmail.com (B. Nasiri-Tabrizi).

http://dx.doi.org/10.1016/j.matlet.2015.01.149

0167-577X/o 2015 Elsevier B.V. All rights reserved.
In the present study, the effect of carbonate concentration on mechanochemical synthesis of pure n-CCAp was examined for the first time. The synthesis of pure n-CCAp reported here can be promising candidate for using in biomedical applications.

\section{Materials and methods}

Calcium carbonate $\left(\mathrm{CaCO}_{3}\right.$, Merck), calcium chloride $\left(\mathrm{CaCl}_{2}\right.$, Merck), and phosphorous pentoxide $\left(\mathrm{P}_{2} \mathrm{O}_{5}\right.$, Merck) were used as precursor materials. Mechanical activation was done in a high-energy planetary ball mill for $10 \mathrm{~h}$ using hardened chromium steel vials (vol. $125 \mathrm{ml}$ ) and balls ( $20 \mathrm{~mm}$ in diameter) under a high-purity argon atmosphere (99.99\% purity). The total powder mass, the weight ratio of ball-topowder (BPR), and rotational speed were $7 \mathrm{~g}, 15: 1$, and $600 \mathrm{rpm}$, respectively. The designed degree of substitution of $\mathrm{PO}_{4}^{3-}$ by $\mathrm{CO}_{3}^{2-}$ was demonstrated by the $x$ value in the general formula of B-type CCAp $\left(\mathrm{Ca}_{10}{ }_{x / 2}\left(\mathrm{PO}_{4}\right)_{6-x}\left(\mathrm{CO}_{3}\right)_{x} \mathrm{Cl}_{2}\right)$, where $x$ values were chosen equal to 0.0 , $0.5,1.0$, and 2 and so the synthesized nanopowders were designated as CCA0, CCA0.5, CCA1, and CCA2, respectively. The general form of the mechanochemical reaction is as follows:

$(9-x / 2) \mathrm{CaCO}_{3}+(3-x / 2) \mathrm{P}_{2} \mathrm{O}_{5}+\mathrm{CaCl}_{2} \rightarrow \mathrm{Ca}_{10-x / 2}\left(\mathrm{PO}_{4}\right)_{6-x}\left(\mathrm{CO}_{3}\right)_{x} \mathrm{Cl}_{2}+(9-3 x / 2) \mathrm{CO}_{2}$

The details of powder components and mole ratio are summarized in Table 1. Phase evaluation was performed by X-ray diffraction (Philips X-ray diffractometer (XRD), Cu-K $\alpha$ radiation, $40 \mathrm{kV}$, 
Table 1

Details of powder components and mole ratio

\begin{tabular}{lllll}
\hline Series & Degree of substitution $\left(\mathrm{Ca}_{10-x / 2}\left(\mathrm{PO}_{4}\right)_{6-x}\left(\mathrm{CO}_{3}\right)_{x} \mathrm{Cl}_{2}\right)$ & Powder component & Mole ratio & \multicolumn{1}{c}{ Phase composition } \\
\hline CCA0 & 0 & $\mathrm{CaCO}_{3}-\mathrm{P}_{2} \mathrm{O}_{5}-\mathrm{CaCl}_{2}$ & $9: 3: 1$ & $\mathrm{Ca}_{10}\left(\mathrm{PO}_{4}\right)_{6} \mathrm{Cl}_{2}$ \\
CCA0.5 & 0.5 & $\mathrm{CaCO}_{3}-\mathrm{P}_{2} \mathrm{O}_{5}-\mathrm{CaCl}_{2}$ & $8.75: 2.75: 1$ & $\mathrm{Ca}_{9.75}\left(\mathrm{PO}_{4}\right)_{5.5}\left(\mathrm{CO}_{3}\right)_{0.5} \mathrm{Cl}_{2}$ \\
CCA1 & 1 & $\mathrm{CaCO}_{3}-\mathrm{P}_{2} \mathrm{O}_{5}-\mathrm{CaCl}_{2}$ & $8.5: 2.5: 1$ & $\mathrm{Ca}_{9.5}\left(\mathrm{PO}_{4}\right)_{5}\left(\mathrm{CO}_{3}\right) \mathrm{Cl}_{2}$ \\
CCA2 & 2 & $\mathrm{CaCO}_{3}-\mathrm{P}_{2} \mathrm{O}_{5}-\mathrm{CaCl}_{2}$ & $8: 2: 1$ & $\mathrm{Ca}_{9}\left(\mathrm{PO}_{4}\right)_{4}\left(\mathrm{CO}_{3}\right)_{2} \mathrm{Cl}_{2}$ \\
\hline
\end{tabular}

a

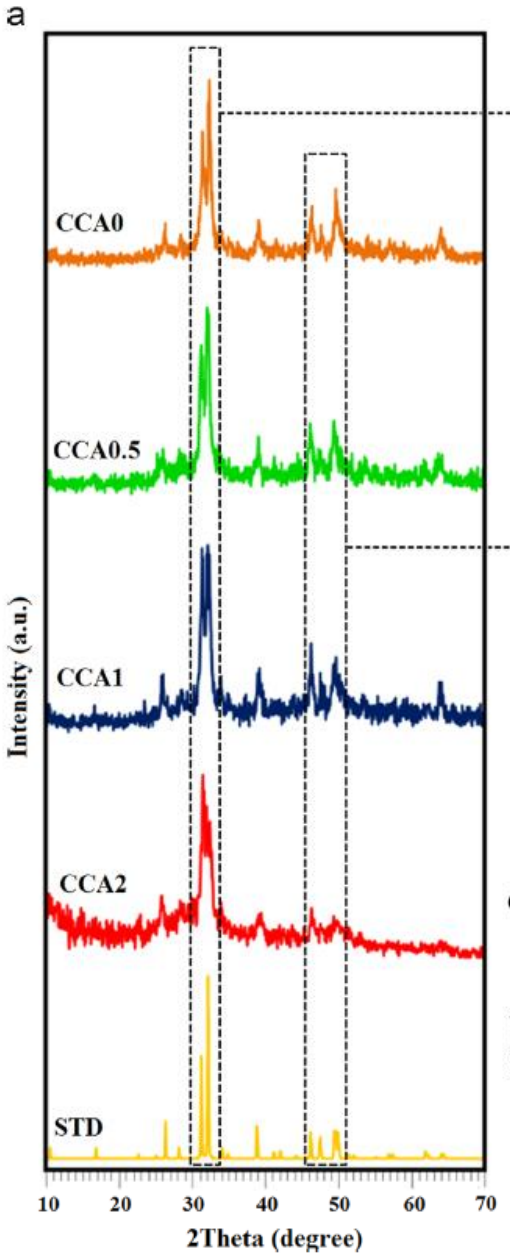

b

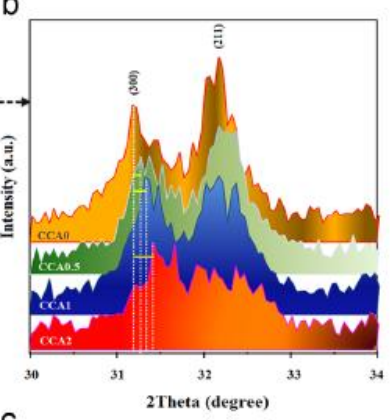

C

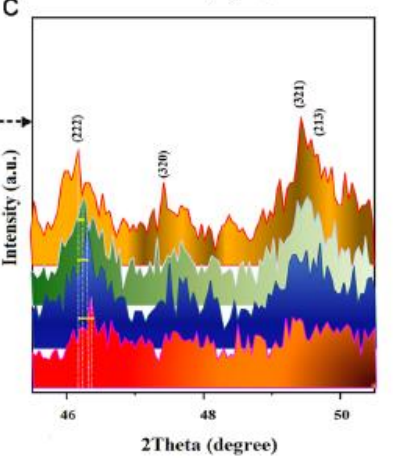

d

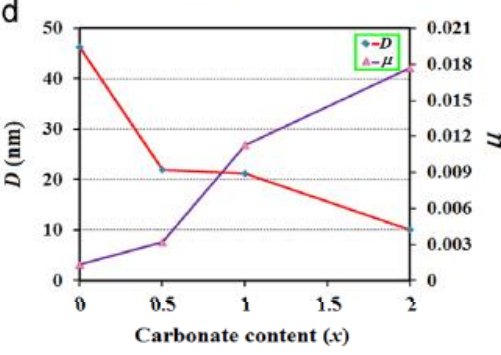

e
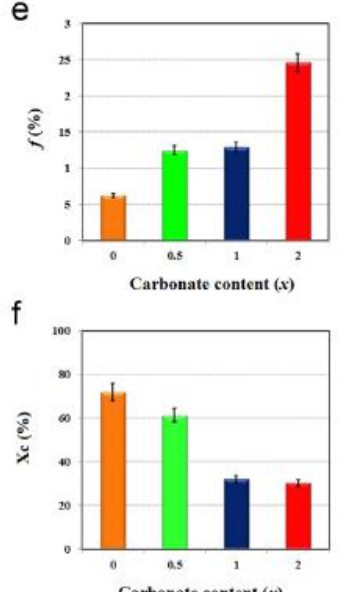

g

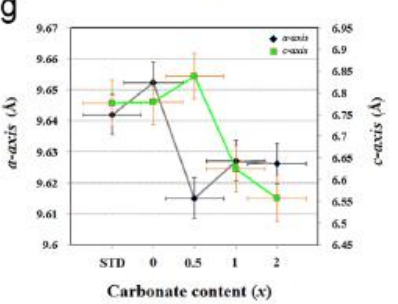

h

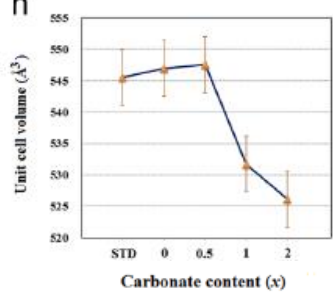

Fig. 1. (a) XRD patterns, (b) magnitude XRD profiles $2 \theta=30-34^{\circ}$ and (c) $2 \theta=45.5-50.5^{\circ}$, (d) crystallite size and lattice strain, (e) volume fraction of grain boundary, (f) crystallinity degrees, and $(\mathrm{g})$ the lattice parameters and $(\mathrm{h})$ unit cell volume of the samples milled for $10 \mathrm{~h}$ with different degrees of substitution.

$30 \mathrm{~mA}, 0.02^{\circ} \mathrm{s}^{-1}$ step scan, and $10^{\circ} \leq 2 \theta \leq 70^{\circ}$ ). The functional groups of n-CCAp were assessed using Fourier transformed infrared spectroscopy (Perkin-Elmer Spectrum 65 FT-IR Spectrometer, USA) in the range of $4000-400 \mathrm{~cm}^{-1}$. Microstructural appraisal of n-CCAp was executed using SEM (SEM, VEGA Tescan easyprobe) and TEM (HT-7700, Hitachi, Japan) that operated at the acceleration voltage of 18 and $60 \mathrm{kV}$, respectively.
3. Results and discussion

The XRD patterns of the samples milled for $10 \mathrm{~h}$ with different degrees of substitution are shown in Fig. 1a. From these profiles, all the peaks belonged to the characteristic peaks of apatite (JCPDS027-0074) However, with increasing the carbonate concentration, some noticeable characteristics can be seen; first, the intensity of the characteristic

Link to Full-Text Articles : 